\title{
EFFECT OF MULTIPLE STAINLESS STEEL CROWNS ON SALIVARY PH, NICKEL, AND CHROMIUM LEVELS
}

\author{
Talat Mohamed Beltagy*
}

\begin{abstract}
Background: The use of stainless steel crowns (SSCs) in pediatric dentistry is widely used. Recently, there has been an increasing ecological and global public health concern associated with environmental contamination by metallic alloys. Aim of the study: To determine the in-vitro and in-vivo effect of multiple stainless steel crowns on the salivary $\mathrm{pH}$, nickel and chromium levels at different periods.
\end{abstract}

Materials and methods: This study consisted of: I-In-vitro study: A total of 200 standard sizes of SSCs were divided into 4 groups (10 samples/each). Each sample/group contained 2, 4, 6, and 8 SSCs, respectively. All SSCs were trimmed $1 \mathrm{~mm}$ circumferentially, smoothed, re-contoured, fitted, and cemented on standard crowns of plastic teeth models. Each group was placed in a closed container containing artificial saliva with a standard $\mathrm{pH}$. II-In-vivo study: A total of 40 patients indicated for SSC restorations were selected, aged 5-9 years. Similar to in-vitro, they were allocated into 4 groups according to the numbers of SSCs restorations used. $5 \mathrm{ml}$ of unstimulated saliva was taken for $\mathrm{pH}$, nickel, and chromium analysis at 5-intervals: baseline, and 1day, 1 week, 2weeks, $1 \mathrm{month}$, and 2-months post-cementation. Data analysis: The mean and standard deviations, one way ANOVA, and the Person correlation coefficient were used. The level of significance was adopted at $\mathrm{p} \leq 0.05$.

Results: In both studies: The more the increase in the number of SSCs, the more the increase in acidity and release of ions. As regards $\mathbf{p H}$ value; within the groups at 5 intervals, there was only a significant difference in groups containing 8 SSCs and 6 SSCs, and between the intervals and the baseline ( $\mathrm{p} \leq 0.05)$. The group that has $8 \mathrm{SSCs}$ recorded the lowest $\mathrm{pH}$ value. Among groups: in-vitro: all groups showed a significant difference during 3-time intervals $(p \leq 0.05)$ except at 2 -months; the difference was not significant $(\mathrm{p}>0.05)$, while in-vivo, the difference was not significant $(\mathrm{p}>0.05)$. As regards the released ions: Within groups, both studies showed a significant difference among all intervals, and between the intervals and the baseline $(\mathrm{p} \leq 0.05)$. Among groups: In-vitro, all groups showed significant differences during the intervals $(\mathrm{p} \leq 0.05)$, while the only period showing no significant difference was at 2 months in the chromium group $(p>0.05)$. The group that has 8 SSCs recorded the highest level and the difference was significant $(\mathrm{p} \leq 0.05)$. The peak level of the released ions and reduced $\mathrm{pH}$ value was at 1day and 1 week for in-vitro and in-vivo study, respectively.

Conclusion: The released nickel and chromium ions were directly proportional to the number of stainless steel crowns whereas the $\mathrm{pH}$ value was inversely proportional. The maximum level recorded was 1 day and 1-week post-cementation for in-vitro and in-vivo study, respectively. The peak released of ions was much lower than the toxic level or the level of dietary intake.

KEYWORDS: biodegradation, nickel-chromium levels, $\mathrm{pH}$, stainless steel crowns, children

\footnotetext{
* Associate Professor of Pediatric Dentistry, Faculty of Dentistry, Kafrelsheikh University
} 


\section{INTRODUCTION}

The oral cavity is an ecosystem that is known to cause the biodegradation of metals as a result of the process of electrochemical breakdown ${ }^{(1)}$. It has been reported that wearing different pediatric metal appliances might lead to the alteration of the salivary levels of electrolytes, with an increase in salivary nickel (Ni) or chromium (Cr) concentrations ${ }^{(2)}$.

The main component of fixed orthodontic appliances, space maintaining bands and loops, and stainless steel crowns (SSCs) is the austenitic stainless steel that contains significant amounts of nickel and chromium ${ }^{(3)}$. Up to100 years, harming potentials like contact allergy and cancer risk of $\mathrm{Ni}$ and $\mathrm{Cr}$ and their compounds have been documented in the literature ${ }^{(4-6)}$.

The components of SSCs include 65-70\% Iron, 17-20\% Chromium, 8-13\% Nickel, less than $2 \%$ of Manganese, Silicon and Carbon. Intra-orally, a little amount of metal ions can be released from SSC, which may act as allergens ${ }^{(7-9)}$.

The metal appliances in pediatric dentistry release metal ions into saliva through electrogalvanic current and saliva acts as a mediator ${ }^{(2,10,11)}$. The release is increased after teeth brushing with an increase in salivary $\mathrm{pH}^{(12)}$. Electrogalvanic reactions "corrosion" release the metal ions due to metal surface destruction. Intrinsic factors of corrosion are determined by the structure and composition of that metal, while extrinsic factors depend upon the environment such as $\mathrm{pH}$, mediator composition, strain, and temperature ${ }^{(13)}$.

A stainless steel crown is the most effective and durable prefabricated metal restoration for restoring the primary molar after caries removal and/or pulp therapy ${ }^{(14,15)}$. Based on the evidence, the salivary and urinary release, and the serum level of $\mathrm{Ni}$ and $\mathrm{Cr}$ from SSCs and different fixed orthodontic appliances are below the toxic level but not up to daily regimen intakes. The maximum amount of $\mathrm{Ni}$ in food and water is approximately 0.21 and 0.04 $\mathrm{mg} /$ day, respectively, while the $\mathrm{Cr}$ is about 0.17 and $0.002 \mathrm{mg} /$ day, respectively ${ }^{(16,17)}$.

Mostly, the preformed SSCs do not have an accurate fit on the treated teeth. Sometimes, the margins' height may interfere with the crown sitting causing pain with gingival blanching. So, the clinician tries to "trim" the excess margins affecting the amount of $\mathrm{Ni}$ and $\mathrm{Cr}$ release and probably reaching it to the critical level, because of integrity disturbance ${ }^{(18,19)}$.

Nickel is one of the main reasons for allergy and approximately $10-28 \%$ of people are allergic to $\mathrm{it}^{(20,21)}$. The nickel and chromium-containing appliance may lead to harmful outcomes such as hypersensitivity and allergic dermatitis, mucosal ulcers, cellular toxicity, lichenoid plaques in buccal mucous adjacent to allergens, asthma and a change in cellular function ${ }^{(22-24)}$. Furthermore, it has a carcinogenic and mutagenic effect ${ }^{(21,25)}$. Severe inflammatory hyperplasia around the crowns, stomatitis, alveolar bone loss, and throat edema, palate, and gums may be also another side effects ${ }^{(26-28)}$. The intra-oral longterm exposure to nickel and chromium-containing appliances may damage the mucosal cells, monocytes, and cultured cells ${ }^{(29-32)}$.

In the past, most of the studies ${ }^{(2,10,11,13,21,23)}$ were conducted to evaluate the salivary release of $\mathrm{Ni}$ and $\mathrm{Cr}$ elements from metal orthodontic appliances but there were rare clinical and laboratory publications about the salivary $\mathrm{pH}$ level, nickel and chromium release from SSCs. Thus, this study was directed to determine, in-vitro and in-vivo, the effect of multiple stainless steel crowns on salivary $\mathrm{pH}$ value, nickel, and chromium levels.

\section{MATERIALS AND METHODS}

This study consists of two parts.

\section{I- In-vitro study}

A total of 200 standard sizes of SSCs (Kids Crown, Shinhung Dental, Seoul, Korea) were used in this part of the study. They were divided into 
4 groups (10 samples/each). Each sample/group had contained 2, 4, 6, and 8 SSCs, respectively.

Initially, all margins of SSCs were trimmed $1 \mathrm{~mm}$ distance from the edge of crowns using a disk under water spray and smoothed by pink mullet and white polish rubber. All crowns were cemented on standard crowns of plastic dental teeth models, using zinc polycarboxylate luting cement (Adhesor Carbofine, Spofa Dental, Prague, CzeCh Republic). Fig 1A.

Each group was placed in a numbered sterilized closed glass container containing $50 \mathrm{ml}$ of artificial saliva with a $\mathrm{pH}$ of $6.43 \pm 0.26$ (fig $1 \mathrm{~B}$ ). The formula of artificial saliva was $0.8 \mathrm{~g} \mathrm{NaCl}, 2.4 \mathrm{~g} \mathrm{KCl}, 1.5$ g NaH2PO4, 0.1 g Na2S, and 2 g CO[NH2]2), that stored in an incubator at $37^{\circ} \mathrm{C}$ for 4 weeks ${ }^{(33)}$. Any adjustment for the standard $\mathrm{pH}$ value is required, an increment of $1 \mathrm{~N}$ sodium hydroxide or $1 \mathrm{~N}$ hydrochloric was added ${ }^{(34)}$. The artificial saliva used was prepared in the Pharmaceutical Chemistry Department, Faculty of Pharmacy, Kafrelesheikh University.

Another two containers containing only the artificial saliva without crowns were used as a baseline. To avoid saturation of the solution, the same samples were removed from each container at the end of each interval and immersed in new containers with freshly prepared artificial saliva. The solutions were replaced weekly during the study period ${ }^{(34)}$. The closed containers containing samples were placed in an incubator (Memert $\mathrm{GmbH}$, Büchenbach, Germany) regulated at $37^{\circ}$ C. All samples were shaken gently during the immersion, to get a uniform solution and to confirm bathing all samples in the artificial saliva ${ }^{(33)}$.

The $\mathrm{pH}$ value of artificial saliva at each interval was measured by a $\mathrm{pH}$ Meter ( $\mathrm{pH}$ Meter 3310, JENWAY, Felsted, Essex, UK) (fig 1C). After each record, the $\mathrm{pH}$ electrode was irrigated, using distilled water and was kept in the kit's standard 7-pH solution ${ }^{(35)}$. It was rinsed and dried before each measurement.

The released $\mathrm{Ni}$ and $\mathrm{Cr}$ elements were measured at each interval using Inductively Coupled Plasma Optical Emission Spectrometry (ICP-OES) Prodigy 7 instrument (Teledyne Leeman Labs, Mason, Ohio, USA) in Geochemistry of Trace and Toxic Elements Lab (accredited according to ISO/IEC (17025/2017), Faculty of Agriculture, Kafrelsheikh University, Egypt (fig1D). Nickel and chromium levels of each sample were measured thrice, and the average was recorded.

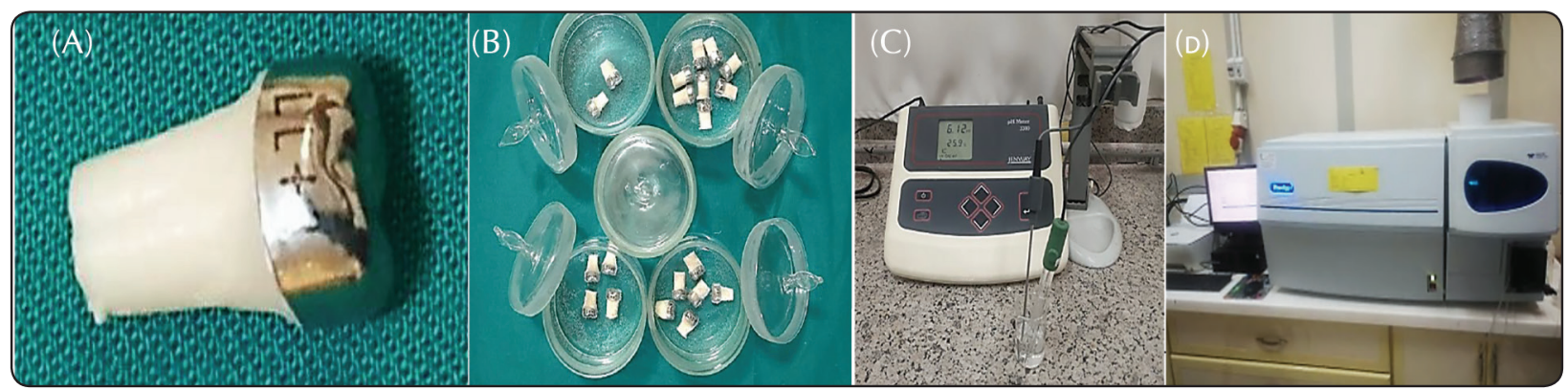

Fig. (1) The cemented SSCs on standard crowns of plastic teeth models after immersion in glass containers contained artificial saliva(A,B), pH Meter 3310 for measurement of $\mathrm{pH}$ value (C), and ICP-OES Prodigy 7 for assessment of released Ni and Crions (D). 


\section{II- In-vivo study}

A total of 40 children of both sexes ( 23 boys and 17 girls), aged 5-9 years (mean ages of $6.5 \pm 1.24$ ) participated in this study from patient attending the clinic of Pediatric Department, Faculty of Dentistry, Kafrelsheikh University.

Informed consent was taken from children's parents according to the proposed Guideline of the Research Ethics Committee, Faculty of dentistry, Kafrelsheikh University. All children's parents participating in this study were thoroughly informed of the objective and procedures of the research. Medical and dental histories were taken.

They were allocated into 4 groups according to the number of SSC restorations used, similar to the in-vitro study. The inclusion criteria were: a clinical indication for conventional preformed SSCs, without any further need for more modification within the next 2-months, and cooperative child according to Frankl rating scale (++) or (+). All inclusion criteria had to be fulfilled during the study period ${ }^{(36)}$.

The exclusion criteria were: patients with any oral or systemic diseases, syndromes, illnesses related to genetic damage, allergies, allergies to costume jewelry, watches, or any other sources of $\mathrm{Ni}$ or $\mathrm{Cr}$, any amalgam fillings or metal restorations, previous orthodontic treatment, patients who received antibiotics or steroids or under local therapy of fluoride, probiotic, and alcohol-based mouthwashes ${ }^{(37)}$.
To standardize the sampling methods ${ }^{(36)}$, oral hygiene maintenance with the use of one type and brand of toothpaste was instructed to all parents and children before the study. There was a need for placing all indicated SSCs in the same session, and a list of nickel-rich foods/drinks were handed to the parents to exclude them within $48 \mathrm{hrs}$ before sampling. They were also asked not to rinse with fluoridated mouthwashes $24 \mathrm{hrs}$ before the next visit, till after sample collection ${ }^{(38-41)}$. The children were directed not to use an oral rinse, not to eat, drink or brush their teeth on the morning of the scheduled visit ${ }^{(36,42)}$. If any patients were dropped out of the study, they would be replaced with new patients.

\section{Preparation of SSCs}

The occlusal surface of SSCs was reduced by 1-1.5 mm and the occlusal third of the buccal surface was beveled using a diamond wheel bur and round of all line angles. The proximal contacts were opened at the appropriate depth in a single sweeping motion, using tapered fissure bur. The properly-selected size of SSCs was just trimmed to flat edges, smoothed, fitted, re-contoured, and crimped. All margins were checked for an accurate fit. All SSCs were cemented with zinc polycarboxylate luting cement, the excess was removed by a sharp instrument, and the occlusion was checked. All treated primary molars underneath the SSCs were 70\% pulpotomy,

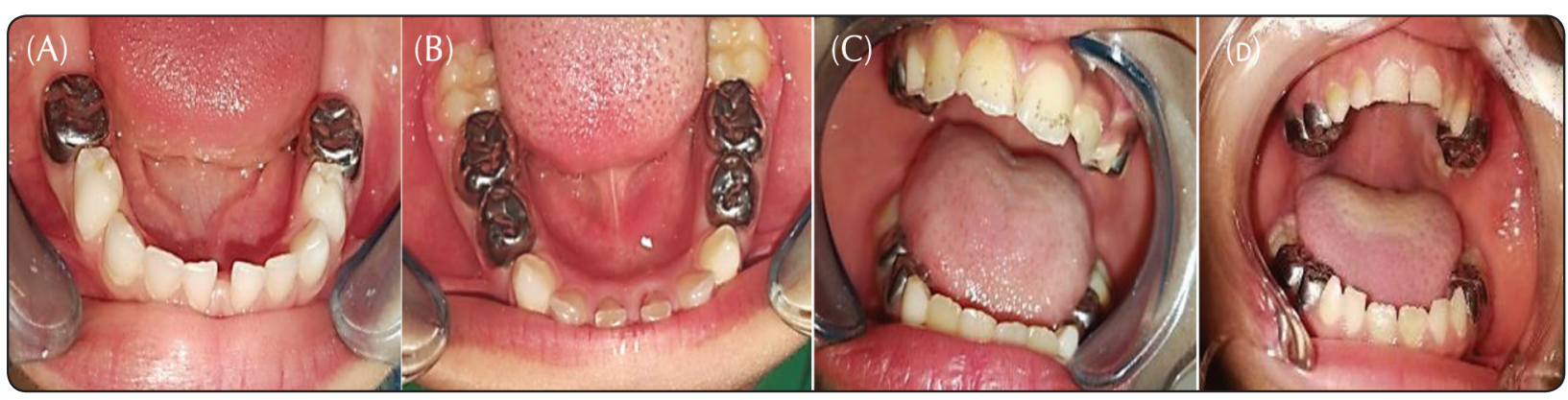

Fig. (2) Photographs represent the 4 groups of the study, respectively (A-D). 
$20 \%$ pulpectomy, and $10 \%$ multi-surface caries restorations and developmental defects.

The before-after clinical trial was carried out on 240 observations from 40 pediatric dental patients, recorded at 6-time points: pre-treatment (baseline) and 1 day, 1 week, 2 weeks, 1 month, and 2 months post-treatment.

\section{Saliva Sampling}

In the morning before breakfast, each patient was instructed to rinse the mouth thoroughly with distilled and deionized water before sampling. In each session, $5 \mathrm{ml}$ of unstimulated saliva was collected within 5 minutes with the mouth closed, then transferred to sterilize nickel/chromium-free polyethylene test tubes by direct spitting ${ }^{(12)}$. The sample divided into two equal parts, one part for analysis of $\mathrm{pH}$ value and the other for analysis of $\mathrm{Ni}$ and $\mathrm{Cr}$ ions. The sampling was undertaken from the patients at 6-time points.

\section{Salivary pH level measurement}

The $\mathrm{pH}$ value was recorded after sampling using $\mathrm{pH}$ meter, to avoid any $\mathrm{pH} / \mathrm{CO} 2$ changes ${ }^{(42)}$. The average of 3 records for each sample was reported.

\section{Salivary ions Measurement}

The samples were transferred to the Geochemistry of Trace and Toxic Elements Lab, Faculty of Agriculture, Kafrelsheikh University, Egypt. At the laboratory, the sample was centrifuged at 50008000 rpm for 5 minutes using Centurion Scientific Benchtop centrifuge (Cole-Parmer, Southampton, Hampshire, UK) and its impurities, debris, and proteins were removed. Then, it was diluted tenfold with $0.1 \%$ nitric acid. Afterward, the salivary Nickel/Chromium concentration of each container was measured thrice using ICP Prodigy7. The average per sample was recorded as the main value $^{(34,35,42,43)}$ was recorded in $\mu \mathrm{g} / \mathrm{L}$ "micrograms per liter ". Noting that $1 \mathrm{ppm}=1000 \mathrm{ppb}, 1 \mathrm{ppm}=1 \mathrm{mg} / \mathrm{L}$, $1 \mathrm{mg}=1000 \mu \mathrm{g}$, and $1 \mathrm{~L}=1000 \mathrm{~mL}$.

\section{Data analysis}

The collected data were organized, tabulated and statistically analyzed using SPSS program, (Statistical Package for Social Studies) version 23.0 ( IBM, Illinois, Chicago, USA). For numerical values, the mean and standard deviations were calculated. The difference within each group at a different time of intervals and the difference between each group at different specific periods were tested using one way ANOVA. Also, the Person correlation coefficient was calculated. The level of significance was adopted at $\mathrm{p} \leq 0.05$.

\section{RESULTS}

Four groups were used in each in-vitro and in-vivo study, each group including 10 samples containing 2, 4, 6, and 8 standard SSCs, respectively. Salivary $\mathrm{pH}$ value, $\mathrm{Ni}$, and $\mathrm{Cr}$ levels were determined at 6-time intervals: pre-treatment (baseline) and 1day, 1 week, 2 weeks, 1 month, and 2 months postcrowns cementation. The age of the patients ranged from 5-9 years with the mean age of 6.5 \pm 1.24 . All patients were available for assessment till the end of the recall.

\section{In-vitro assessment:}

\section{pH/ Ion Measurement}

Table 1. The more the increase in the number of SSCs, the more the increase in acidity. According to $\mathrm{pH}$ value, within the groups at the 5-time intervals, there was only a significant difference in the $\mathrm{pH}$ value in two groups; IV (8 SSCs) and III (6 SSCs), and also between intervals and baseline in both groups $(\mathrm{p} \leq 0.05)$. Among the groups at the different specific intervals, group IV (8 SSCs) recorded the lowest $\mathrm{pH}$ value and the difference was significant among them $(\mathrm{p} \leq 0.05)$. All groups showed a significant difference at 4 of the 5 -intervals $(\mathrm{p} \leq 0.05)$ except at 2 months, 
and the difference was not significant among them $(\mathrm{p}>0.05)$.

Tables 2\&3. As regards the released $\mathrm{Ni}$ and $\mathrm{Cr}$ ions, the released elements were directly proportional to the number of SSCs in the synthetic saliva. All groups showed a significant increase in the released ions during the first phase post- cementation, thereafter, they decreased gradually during the time intervals but the significance was still higher than the baseline ( $\mathrm{p} \leq 0.05)$. The group IV (8 SSCs) recorded the highest level of significance $(\mathrm{p} \leq 0.05)$. The peak of acidity, nickel, and chromium levels was seen at 1-day post-cementation.

TABLE (1) In-vitro: Comparison of $\mathrm{pH}$ value during the follow-up period

\begin{tabular}{|c|c|c|c|c|c|c|}
\hline \multirow{2}{*}{$\begin{array}{c}\text { Follow-up } \\
\text { period }\end{array}$} & \multicolumn{4}{|c|}{ Mean \pm standard deviation } & \multirow[t]{2}{*}{$\mathrm{F}$} & \multirow[t]{2}{*}{$\mathrm{P}$} \\
\hline & Group I & Group II & Group III & Group IV & & \\
\hline Baseline & $6.43 \pm 1.44$ & $6.43 \pm 1.70$ & $6.43 \pm 0.15$ & $6.43 \pm 0.75$ & 0.356 & 0.073 \\
\hline 1 day & $5.30+0.95$ & $4.68+0.89$ & $3.56+0.22$ & $3.09+0.49$ & 27.356 & $0.001 *$ \\
\hline 1 week & $5.88 \pm 1.46$ & $5.41 \pm 1.47$ & $4.34 \pm 1.55$ & $3.93 \pm 1.13$ & 10.852 & $0.013 *$ \\
\hline 2 weeks & $5.71 \pm 0.84$ & $5.22 \pm 1.21$ & $4.12 \pm 1.04$ & $4.80 \pm 0.72$ & 17.081 & $0.001 *$ \\
\hline 1 month & $6.04 \pm 0.62$ & $5.80 \pm 0.85$ & $4.73 \pm 1.31$ & $5.41 \pm 1.05$ & 10.792 & $0.013 *$ \\
\hline 2 months & $6.40 \pm 1.53$ & $6.29 \pm 1.93$ & $6.21 \pm 0.96$ & $6.14 \pm 1.67$ & 0.222 & 0.974 \\
\hline $\mathrm{F}$ & 6.948 & 9.714 & 31.600 & 25.086 & & \\
\hline $\mathrm{P}$ & 0.225 & 0.084 & $0.001 *$ & $0.001 *$ & & \\
\hline
\end{tabular}

$F=F$ value $\quad *$ Significant at $p \leq 0.05$

TABLE (2) In-vitro: Comparison of Nickel level during the follow-up period $(\mu \mathrm{g} / \mathrm{L})$

\begin{tabular}{|c|c|c|c|c|c|c|}
\hline \multirow{2}{*}{$\begin{array}{c}\text { Follow-up } \\
\text { period }\end{array}$} & \multicolumn{4}{|c|}{ Mean \pm standard deviation } & \multirow{2}{*}{$\mathrm{F}$} & \multirow{2}{*}{$\mathrm{P}$} \\
\hline & Group I & Group II & Group III & Group IV & & \\
\hline Baseline & 0.0 & 0.0 & 0.0 & 0.0 & - & - \\
\hline 1 day & $1.73+0.61$ & $3.22+1.80$ & $4.98+1.07$ & $6.00+1.61$ & 24.380 & $0.001 *$ \\
\hline 1 week & $1.22+0.39$ & $2.28+0.82$ & $3.58+1.05$ & $5.28+1.53$ & 23.541 & $0.001 *$ \\
\hline 2 weeks & $1.19 \pm 0.34$ & $2.22 \pm 0.95$ & $3.47 \pm 1.31$ & $4.10 \pm 0.89$ & 24.264 & $0.001 *$ \\
\hline 1 month & $0.77 \pm 0.36$ & $1.43 \pm 0.77$ & $2.43 \pm 0.75$ & $2.98 \pm 0.95$ & 32.963 & $0.001 *$ \\
\hline 2 months & $0.21 \pm 0.04$ & $0.28 \pm 0.04$ & $0.40 \pm 0.08$ & $0.55 \pm 0.07$ & 17.103 & $0.001 *$ \\
\hline $\mathrm{F}$ & 43.797 & 39.543 & 42.629 & 44.914 & & \\
\hline $\mathrm{P}$ & $0.001 *$ & $0.001 *$ & $0.001 *$ & $0.001 *$ & & \\
\hline
\end{tabular}


TABLE (3) In-vitro: Comparison of Chromium level during the follow-up period $(\mu \mathrm{g} / \mathrm{L})$

\begin{tabular}{|c|c|c|c|c|c|c|}
\hline \multirow{2}{*}{$\begin{array}{c}\text { Follow-up } \\
\text { period }\end{array}$} & \multicolumn{4}{|c|}{ Mean \pm standard deviation } & \multirow{2}{*}{$\mathrm{F}$} & \multirow{2}{*}{$\mathrm{P}$} \\
\hline & Group I & Group II & Group III & Group IV & & \\
\hline Baseline & 0.0 & 0.0 & 0.0 & 0.0 & - & - \\
\hline 1 day & $0.57 \pm 0.11$ & $1.14 \pm 0.57$ & $1.62 \pm 0.46$ & $1.98 \pm 0.44$ & 22.720 & $0.001^{*}$ \\
\hline 1 week & $1.01 \pm 0.14$ & $2.02 \pm 0.62$ & $2.61 \pm 1.02$ & $3.48 \pm 1.29$ & 24.694 & $0.001 *$ \\
\hline 2 weeks & $0.63 \pm 0.13$ & $1.25 \pm 0.57$ & $1.77 \pm 0.45$ & $2.17 \pm 0.47$ & 25.738 & $0.001^{*}$ \\
\hline 1 month & $0.44 \pm 0.18$ & $0.87 \pm 0.10$ & $1.19 \pm 0.11$ & $1.50 \pm 0.80$ & 36.316 & $0.001^{*}$ \\
\hline 2 months & $0.15 \pm 0.23$ & $0.18 \pm 0.05$ & $0.23 \pm 0.03$ & $0.33 \pm 0.05$ & 34.134 & $0.001 *$ \\
\hline $\mathrm{F}$ & 43.453 & 40.702 & 43.314 & 43.314 & & \\
\hline $\mathrm{P}$ & $0.001 *$ & $0.001 *$ & $0.001 *$ & $0.001 *$ & & \\
\hline
\end{tabular}

$F=F$ value $\quad$ Significant at $p<0.0$

\section{In-vivo assessment:}

\section{pH/Ion Measurement}

Table 4 showed that there was no significant change in $\mathrm{pH}$ in group I (2 SSCs) and II (4SSCs) during all intervals and between the intervals and the baseline $(p>0.05)$, but the difference was significant in group IV (8 SSCs) and group III (6 SSCs) ( $\mathrm{p} \leq 0.05)$.
The group, that has 8 SSCs (IV), recorded the lowest $\mathrm{pH}$ value than the other groups, but the difference was not significant ( $\mathrm{p}>0.05)$.

The peak reduction level was recorded at 1-week post-treatment for all groups, thereafter; the $\mathrm{pH}$ value was gradually increased to be near the baseline at 2 months interval.

TABLE (4) In-vivo: Comparison of $\mathrm{pH}$ value during follow-up period

\begin{tabular}{|c|c|c|c|c|c|c|}
\hline \multirow{2}{*}{$\begin{array}{c}\text { Follow-up } \\
\text { period }\end{array}$} & \multicolumn{4}{|c|}{ Mean \pm standard deviation } & \multirow{2}{*}{$\mathrm{F}$} & \multirow{2}{*}{$\mathrm{P}$} \\
\hline & Group I & Group II & Group III & Group IV & & \\
\hline Baseline & $6.87 \pm 1.73$ & $6.79 \pm 1.51$ & $6.91 \pm 0.97$ & $6.81 \pm 1.67$ & 0.329 & 0.954 \\
\hline 1 day & $6.01 \pm 1.01$ & $5.60 \pm 0.98$ & $5.61 \pm 1.31$ & $4.99 \pm 1.01$ & 5.014 & 0.171 \\
\hline 1 week & $6.01 \pm 1.01$ & $5.30 \pm 1.76$ & $4.51 \pm 0.84$ & $4.10 \pm 0.94$ & 6.496 & 0.171 \\
\hline 2 weeks & $6.73 \pm 1.27$ & $6.41 \pm 1.13$ & $6.01 \pm 0.96$ & $5.50 \pm 1.31$ & 4.387 & 0.223 \\
\hline 1 month & $6.65 \pm 0.64$ & $6.55 \pm 1.15$ & $7.13 \pm 1.81$ & $6.12 \pm 1.40$ & 3.207 & 0.361 \\
\hline 2 months & $6.73 \pm 1.39$ & $6.73 \pm 0.94$ & $6.61 \pm 1.47$ & $6.61 \pm 0.78$ & 0.298 & 0.960 \\
\hline $\mathrm{F}$ & 9.613 & 0.7600 & 15.829 & 24.343 & & \\
\hline $\mathrm{P}$ & 0.087 & 0.180 & $0.001 *$ & $0.001 *$ & & \\
\hline
\end{tabular}


Within groups at the different 5 recalls, there was a significant difference in the level of the released ions among the recall times and between the recalls and the baseline $(\mathrm{p} \leq 0.05)$. Tables $5 \& 6$.

Among groups, there was a significant difference in the level of the released ions post-treatment among the 4-recall and between the recalls and the baseline ( $\mathrm{p} \leq 0.05)$, however, this difference was not significant at 2 months of recall $(p>0.05)$.
Group IV, that has 8 SSCs, recorded the highest level for both trace elements compared to the other groups, and the difference was significant among them $(\mathrm{p} \leq 0.05)$.

The peak level of released ions was recorded at 1-week post-treatment, which decreased gradually afterward during recalls and the difference was significant $(\mathrm{p} \leq 0.05)$.

TABLE (5) In-vivo: Comparison of Nickel level during follow-up period ( $\mu \mathrm{g} / \mathrm{L})$

\begin{tabular}{|c|c|c|c|c|c|c|}
\hline \multirow{2}{*}{$\begin{array}{l}\text { Follow-up } \\
\text { period }\end{array}$} & \multicolumn{4}{|c|}{ Mean \pm standard deviation } & \multirow{2}{*}{$\mathrm{F}$} & \multirow{2}{*}{$\mathrm{P}$} \\
\hline & Group I & Group II & Group III & Group IV & & \\
\hline Baseline & $4.90 \pm 2.38$ & $4.12 \pm 1.97$ & $4.32 \pm 1.40$ & $4.90 \pm 1.47$ & 0.472 & 0.705 \\
\hline 1 day & $11.87 \pm 2.88$ & $20.91 \pm 6.90$ & $34.87 \pm 19.14$ & $43.67 \pm 19.30$ & 12.28 & $0.001 *$ \\
\hline 1 week & $12.99+3.05$ & $22.95 \pm 3.87$ & $37.09+12.40$ & $51.00+19.30$ & 20.012 & $0.001 *$ \\
\hline 2 weeks & $9.10 \pm 1.88$ & $17.68 \pm 5.74$ & $25.77 \pm 9.00$ & $32.79 \pm 15.79$ & 11.411 & $0.001 *$ \\
\hline 1 month & $7.60 \pm 2.81$ & $10.40 \pm 4.90$ & $16.60 \pm 14.44$ & $19.30 \pm 6.63$ & 4.110 & $0.005^{*}$ \\
\hline 2 months & $5.42 \pm 1.36$ & $4.89 \pm 2.03$ & $4.85 \pm 0.85$ & $5.99 \pm 2.22$ & 0.990 & 0.409 \\
\hline $\mathrm{F}$ & 37.771 & 40.286 & 35.714 & 41.657 & & \\
\hline $\mathrm{P}$ & $0.001 *$ & $0.001 *$ & $0.001 *$ & $0.001 *$ & & \\
\hline
\end{tabular}

$F=F$ value

*Significant at $p \leq 0.05$

TABLE (6) In-vivo: Comparison of Chromium level during follow-up ( $\mu \mathrm{g} / \mathrm{L})$

\begin{tabular}{|c|c|c|c|c|c|c|}
\hline \multirow{2}{*}{$\begin{array}{c}\text { Follow-up } \\
\text { period }\end{array}$} & \multicolumn{4}{|c|}{ Mean \pm standard deviation of chromium } & \multirow{2}{*}{ F } & \multirow{2}{*}{ P } \\
\cline { 2 - 6 } & Group I & Group II & Group III & Group IV & & 0.46 \\
\hline Baseline & $0.32 \pm 0.20$ & $0.38 \pm 0.07$ & $0.35 \pm 0.10$ & $0.39 \pm 0.15$ & 0.710 \\
\hline 1 day & $1.63 \pm 0.77$ & $3.01 \pm 1.69$ & $6.72 \pm 2.79$ & $8.89 \pm 2.08$ & 12.18 & $0.001 *$ \\
\hline 1 week & $1.85 \pm 0.80$ & $2.63 \pm 1.25$ & $4.19 \pm 1.59$ & $7.02 \pm 3.66$ & 25.14 & $0.001 *$ \\
\hline 2 weeks & $0.88 \pm 0.25$ & $1.76 \pm 1.83$ & $3.02 \pm 1.64$ & $5.49 \pm 1.84$ & 16.93 & $0.001 *$ \\
\hline 1 month & $0.62 \pm 0.11$ & $1.57 \pm 1.33$ & $2.17 \pm 1.28$ & $3.47 \pm 1.39$ & 10.60 & $0.001 *$ \\
\hline 2 months & $0.40 \pm 0.08$ & $0.51 \pm 0.27$ & $0.45 \pm 0.12$ & $0.43 \pm 0.09$ & 0.83 & 0.486 \\
\hline F & 40.279 & 28.800 & 40.000 & 40.971 & & \\
\hline P & $0.001 *$ & $0.001 *$ & $0.001 *$ & $0.001 *$ & & \\
\hline
\end{tabular}


The correlation coefficient between the in-vitro and in-vivo results is displayed in table 7. The peak value of the correlation between the two parts of the study was observed at 1-week of the time interval for $\mathrm{pH}$ value, however, it was found at 1-week for $\mathrm{Ni}$ and at 2-month for Cr post-treatment, where rank 1 was recorded for both $\mathrm{pH}$ value and $\mathrm{Ni}$ level, but rank 2 was recorded for $\mathrm{Cr}$ level. The $\mathrm{Cr}$ group was strongly correlated during all intervals.

The correlation coefficients at the first phase of treatment (1-week time interval) showed that, in both parts of this study, there was a negative correlation between the $\mathrm{pH}$ value and $\mathrm{Cr}$ release, and only invivo with Ni release. There was a strong correlation between the released $\mathrm{Cr}$ in both parts of the study, and between released $\mathrm{Ni}$ in both parts of the study. The Cr released in-vitro showed a moderate positive correlation with Ni release in both parts of the study. Table 8 .
TABLE (7) Correlation coefficients between in vitro and in-vivo results regarding $\mathrm{pH}$ value, $\mathrm{Ni}$, and $\mathrm{Cr}$ levels during follow-up period.

\begin{tabular}{|c|c|c|c|}
\hline \multicolumn{4}{|c|}{$\mathrm{pH}$} \\
\hline Follow-up period & Correlations & $P$ value & Rank \\
\hline 1day & 0.15 & 0.494 & 5 \\
\hline 1week & 0.45 & $0.004 *$ & 1 \\
\hline 2 weeks & 0.38 & $0.014 *$ & 2 \\
\hline 1month & 0.14 & 0.396 & 4 \\
\hline 2 months & 0.15 & 0.369 & 3 \\
\hline \multicolumn{4}{|c|}{$\mathrm{Ni}$} \\
\hline Follow-up period & Correlations & $P$ value & Rank \\
\hline 1day & 0.57 & $0.000^{*}$ & 2 \\
\hline 1week & 0.43 & $0.000^{*}$ & 1 \\
\hline 2weeks & 0.40 & $0.007 *$ & 4 \\
\hline 1month & 0.38 & $0.016^{*}$ & 4 \\
\hline 2 months & 0.24 & 0.141 & 5 \\
\hline \multicolumn{4}{|c|}{$\mathrm{Cr}$} \\
\hline Follow-up period & Correlations & $P$ value & Rank \\
\hline 1 day & 0.45 & $0.004 *$ & 5 \\
\hline 1 week & 0.74 & $0.000^{*}$ & 4 \\
\hline 2 weeks & 0.64 & $0.000^{*}$ & 2 \\
\hline 1 month & 0.65 & $0.000^{*}$ & 3 \\
\hline 2 months & 0.80 & $0.000 *$ & 1 \\
\hline
\end{tabular}

pH=Potential of Hydrogen Ni=Nickel Cr=Chromium *Significant at $p \leq 0.05$

TABLE (8) Correlation coefficients between salivary $\mathrm{pH}, \mathrm{Ni}$, and $\mathrm{Cr}$ levels at 7-week interval.

\begin{tabular}{|l|l|r|r|r|r|r|r|}
\hline \multicolumn{2}{|c|}{} & Cr in-vivo & Cr in-vitro & Ni in-vivo & Ni in-vitro & pH in-vivo & pH in-vitro \\
\hline \multirow{3}{*}{ Cr in-vivo } & Pearson Correlation & 1 & $.639^{*}$ & $.645^{*}$ & $.606^{*}$ & $-.326^{*}$ & $-.326^{*}$ \\
\cline { 2 - 8 } & Sig. (2-tailed) & & .000 & .000 & .000 & .040 & .040 \\
\cline { 2 - 8 } & $\mathrm{N}$ & 40 & 40 & 40 & 40 & 40 & 40 \\
\hline \multirow{3}{*}{ Cr in-vitro } & Pearson Correlation & $.639^{*}$ & 1 & $.550^{*}$ & $.421^{*}$ & $-.343^{*}$ & $-.343^{*}$ \\
\cline { 2 - 8 } & Sig. (2-tailed) & .000 & & .000 & .007 & .030 & .030 \\
\cline { 2 - 8 } & N & 40 & 40 & 40 & 40 & 40 & 40 \\
\hline \multirow{3}{*}{ Ni in-vivo } & Pearson Correlation & $.645^{*}$ & $.550^{*}$ & 1 & $.708^{*}$ & -.309 & -.309 \\
\cline { 2 - 8 } & Sig. (2-tailed) & .000 & .000 & & .000 & .052 & .052 \\
\cline { 2 - 8 } & $\mathrm{N}$ & 40 & 40 & 40 & 40 & 40 & 40 \\
\hline
\end{tabular}




\begin{tabular}{|c|c|c|c|c|c|c|c|}
\hline & & $\mathrm{Cr}$ in-vivo & $\mathrm{Cr}$ in-vitro & Ni in-vivo & $\mathbf{N i}$ in-vitro & pH in-vivo & pH in-vitro \\
\hline \multirow[t]{3}{*}{ Ni in-vitro } & Pearson Correlation & $.606^{*}$ & $.421^{*}$ & $.708^{*}$ & 1 & .015 & .015 \\
\hline & Sig. (2-tailed) & .000 & .007 & .000 & & .927 & .927 \\
\hline & $\mathrm{N}$ & 40 & 40 & 40 & 40 & 40 & 40 \\
\hline \multirow[t]{3}{*}{ pH in-vivo } & Pearson Correlation & $-.326^{*}$ & $-.343^{*}$ & -.309 & .015 & 1 & $1.000^{*}$ \\
\hline & Sig. (2-tailed) & .040 & .030 & .052 & .927 & & .000 \\
\hline & $\mathrm{N}$ & 40 & 40 & 40 & 40 & 40 & 40 \\
\hline \multirow[t]{3}{*}{ pH in-vitro } & Pearson Correlation & $-.326^{*}$ & $-.343^{*}$ & -.309 & .015 & $1.000^{*}$ & 1 \\
\hline & Sig. (2-tailed) & .040 & .030 & .052 & .927 & .000 & \\
\hline & $\mathrm{N}$ & 40 & 40 & 40 & 40 & 40 & 40 \\
\hline
\end{tabular}

*. Correlation is significant at the 0.05 level (2-tailed).

pH=Potential of Hydrogen Ni=Nickel Cr=Chromium

\section{DISCUSSION}

Some heavy metals such as nickel and chromium are widely distributed toxic industrial ions, posing environmental and occupational exposure risks leading to harmful outcomes. The exposure may be due to direct contact with the contaminated soil, water, air, and food, or by absorption through the skin or mucous membrane as a result of manufacturing, pharmaceutical, or industrial processes or consumer products such as stainless steel, magnets, coins, and alloys ${ }^{(44-46)}$.

In pediatric dentistry, the stainless steel used in the manufacture of SSCs, bands, orthodontic braces, metal appliances, and wires. Intra-orally, most of these metals can be expected to undergo biodegradation by electrochemical breakdown with salivary releasing of $\mathrm{Ni}$ and $\mathrm{Cr}$ ions. Also, the most significant human exposure to $\mathrm{Ni}$ and $\mathrm{Cr}$ occurs through dietary intake. So, the sum of ions consumption as a result of both dietary intake and metal-induced appliances are the most common cause of harmful allergic, cytotoxic, genotoxic, and possibly mutagenic effects ${ }^{(47-51)}$ associated with the metallic taste and the change of salivary $\mathrm{pH}$ value.
Despite, the presence of advanced technology in quality, composition, biocompatibility, and durability of alloys used in dental appliances, the increase of allergic and toxic reactions relating to this issue has been reported ${ }^{(52)}$ with the remaining of its effects intra-orally for 6-months ${ }^{(53)}$.

According to the previous and present study, the amount of $\mathrm{Ni}$ and $\mathrm{Cr}$ released from SSC in the invitro and in vivo study is not critical, but placing multiple SSCs intraoral in child at the same time or the simultaneous presence of crowns, space maintainers and orthodontic appliances may cause $\mathrm{Ni}$ and $\mathrm{Cr}$ release exceeding critical limits ${ }^{(15,54)}$. Thus, this study aimed to evaluate the in-vitro and in-vivo effect of multiple SSCs on the salivary levels of $\mathrm{pH}, \mathrm{Ni}$, and $\mathrm{Cr}$ at different periods.

Most of the dental general practitioners are using the traditional SSCs which required trimming and contouring to avoid gingival blanching, pain, gingivitis, and periodontitis. This trimming may affect the amount of $\mathrm{Ni}$ and $\mathrm{Cr}$ release and probably reach a critical level ${ }^{(18,19)}$. Therefore, in this study, we intentionally removed circumferentially $1 \mathrm{~mm}$ from all margins of SSCs. 
In this in-vitro study, a saliva substitute was prepared chemically with a standard value of $\mathrm{pH}$ as a replacement medium for the natural saliva. Besides, all SSCs were cemented on the standard crowns of plastic dental teeth models using conventional cement of adhesor carbofine zinc polycarboxylate. To mimic the intra-oral temperature, all the samples were kept in an incubator at $37^{\circ} \mathrm{C}{ }^{(4)}$. Natural saliva may be affected by many physiologic variables such as health conditions and medications.

The salivary analysis is the most significant method for detecting the level of trace metal elements rather than the blood, urine, epithelial cells, and hair analysis. It has several advantages being the first diluents of the human body, allowing a longer period of analysis with no invasive matrix, no risk of infection, and not needing a special handling or preservation condition ${ }^{(53,55,56)}$. Therefore, in the present study, the saliva sample was used as a method for $\mathrm{pH}$, nickel, and chromium analysis.

In this in-vivo study, the saliva sample was collected by the unstimulated method because the stimulation could change the protein composition of saliva and both $\mathrm{Ni}$ and $\mathrm{Cr}$ had a rapid tendency to combine with protein, which might affect the salivary level of ions ${ }^{(57)}$. However, saliva in the stimulated method had different compositions because all salivary glands were stimulated. Thus, the unstimulated salivary samples were preferred to calculate the actual concentration of nickel and chromium in flowing saliva ${ }^{(58)}$.

The ICP-OES Prodigy 7 instrument was used in this study to analyze $\mathrm{Ni}$ and $\mathrm{Cr}$ release instead of Atomic absorption spectrophotometer, Ultraviolet spectrophotometry, and Calirometric analysis, as it offers all of the advanced capabilities to give high-quality data with a highly sensitive detection method. It measures the trace metal elements by parts per billion (ppb) not by parts per million $(\mathrm{ppm})^{(59)}$.

The main advantage of the in-vitro part of this study is that it can easily standardize all the variables which are difficult to control in-vivo. Meanwhile, the in-vivo part has many advantages as the artificial saliva undergoes precipitation over a period of time and is not allowed to flow through the system as intraoral and the release of any salivary ion is affected by many factors such as $\mathrm{pH}$, quantity and temperature of saliva, microflora, chemical and physical properties of food and drink, and the general oral health condition, which could give a better and reliable result ${ }^{(60)}$. Therefore, this study had in-vitro and in vivo part to complement each other to obtain guaranteed results.

Because most of the studies reported that the salivary nickel and chromium levels peak at the first months post-treatment ${ }^{(4,23,36,38,52,60)}$, especially at the first one, and might tend to reduce later "back to baseline levels or lower". Thus, the 2 months were selected as a recall end interval in this study.

The relation between salivary $\mathrm{pH}$ value and nickel-chromium release from oral metal appliances is still controversial, and it is not quite known which one affects the other. In this in-vitro study, it was found that there was an inverse relationship between the $\mathrm{pH}$ value and the ions release. The lower the acidity, the more the release of $\mathrm{Ni}$ and $\mathrm{Cr}$ ions. This is in agreement with the study of Menek et al. ${ }^{(23)}$ who reported a significant increase in ions discharges when the environment was acidic. This may be explained by the constant disruption of the formed anti-oxide film ${ }^{(23)}$. Other mechanisms may be factors such as corrosion of $\mathrm{Ni}$ and $\mathrm{Cr}$, and the simple redox reaction with the surrounding, which can be strengthened by the acidic $\mathrm{pH}$ caused by dietary intake of acidic foods/drinks or by anaerobic biofilm activities ${ }^{(61,62)}$.

The available publications on ions leached from multiple SSCs were highly controversial. The laboratory studies were limited to only Ni-release. In this study, the mean of $\mathrm{Ni}$ and $\mathrm{Cr}$ levels in artificial saliva was determined. The peak levels of both ions were leached at the first phase of treatment that declined gradually towards the end of the interval. 
This is in accordance with the studies of Kulkarni et al. ${ }^{(33)}$ who assessed the Ni release over 4 weeks and asserted that the peaks around the 1day that decrease gradually afterwards, and Ramazani et al. ${ }^{(52)}$ who studied the Ni release over a month and asserted that the peak of ion level is on the 1day which declined to less than the half in the 7 day, and then reached zero in further intervals.

In this study, the level of $\mathrm{Ni}$ and $\mathrm{Cr}$ released was directly proportional to the number of SSCs. The group, that has 8SSCs, showed a more significant increase in $\mathrm{Ni}$ and $\mathrm{Cr}$ release compared to $6 \mathrm{SSCs}$, 4 SSCs, and 2SSCs. This agrees with Ramazani et al. ${ }^{(52)}$ and Menek et al. ${ }^{(23)}$ who reported a steady increase of $\mathrm{Ni}$ release over time from SSCs immersed in artificial saliva. Furthermore, the corrosion of the steel crowns may play a role in the release as confirmed by the in-vitro study of Dunlap et al. ${ }^{(54)}$ who reported the corrosion potential of metal appliances.

In-vivo, the salivary $\mathrm{pH}$ value became more acidic after SSCs cementation and reached a peak at the first phase of treatment. This may be attributed to the leach of the acid cement which releases peaks around the first week post-treatment and due to cement dissolution resulting from lack of adequate marginal adaptation ${ }^{(52)}$. This finding agrees with Menek et al. ${ }^{(23)}$ who postulated that when the environment was acidic, the formed anti-oxide film was disrupted constantly, leading to a steady increase of nickel leach. Meanwhile, the slight decrease in $\mathrm{pH}$ value was correlated negatively with the increases in Ni-Cr amounts. This agrees with the study of Basir et al. ${ }^{(15)}$. A possible explanation by Basir et al. ${ }^{(15)}$ who found that the more the intense changes in $\mathrm{pH}$ value the more the increase of the redox corrosion of nickel. The observed declines in $\mathrm{pH}$ would accompany enhanced leach of nickel and chromium ions that reflect their elevated levels as basic ions in this study.

In this in-vivo study, the levels of both metal ions were significantly higher in children receiving SSCs at the first 4-time intervals than the levels in the baseline. The SSCs friction such as interproximal and intraoral wear during mastication may lead to a greater surface corrosion and increase the release of sizeable amounts of salivary $\mathrm{Ni}$ and $\mathrm{Cr}$ elements ${ }^{(63)}$. This interpretation is consistent with the interpretation of Bhaskar and Subba Reddy ${ }^{(64)}$, and $\mathrm{Yu}$ et al. ${ }^{(65)}$ who explained that stainless steel is a corrosion resistance family of iron alloys that have a minimum of $10.5 \%$ chromium. Chromium in SSCs plays a dominant role in reacting with oxygen and moisture intraoral and air to form anticorrosive passive chromium III oxide film, approximately 1-5 nanometres thick, on the steel surface. This film protects SSCs from further attack by additional corrosion. If this film is repeatedly damaged or disturbed by cutting, abrasion or scratching during functional demand, additional corrosion with more nickel and chromium release will happen.

Furthermore, the maximum level of released ions in this study was found at 1 day for in-vitro and 1-week for in-vivo post-cementation, respectively, and the release was gradually diminished with the time interval. This may be attributed to the quickly surface corrosion of $\mathrm{Ni}$ and $\mathrm{Cr}$ on SSCs during the first phase of treatment; thereafter, the rate of release drops off as the surface $\mathrm{Ni}$ and $\mathrm{Cr}$ was depleted ${ }^{(16,64)}$. The passive layer of oxide formed leached $\mathrm{Cr}$ on exposure to potentially damaging chemicals and physical agents intraoral ${ }^{(58)}$. This finding is in accordance with the studies of Singh et al. ${ }^{(66)}$, Sfondrini et al. ${ }^{(67)}$, and Yassaei et al. ${ }^{(68)}$ who found the maximum release was after 1 weak, in the first phase of treatment, and after 20 days of appliances insertion, respectively. On the contrary, few studies reporting lower salivary Chromium levels ${ }^{(15,69,70)}$.

The present study showed that the maximum release of both ions was found at the group containing 8 SSCs. This may be because the release of $\mathrm{Ni}$ and $\mathrm{Cr}$ elements is directly proportional to the metal surface area exposed to the intra-oral environment; therefore, the available amount of both elements was increased for corrosion. This agrees with the study of and Mohamed et al. ${ }^{(58)}$ and Bhaskar and 
Reddy ${ }^{(64)}$ who reported that the release of $\mathrm{Ni}$ and Cr elements was directly proportional to the number of metal appliances used. But the finding of this study disagrees with Basir et al. ${ }^{(15)}$ who reported no significant correlations between the number of steel crowns and both ions.

Furthermore, this study showed a negative correlation between salivary $\mathrm{pH}$, and $\mathrm{Ni}-\mathrm{Cr}$ levels at 1 -week post-cementation in both parts of the study. The more the increase in released ions, the more reduced in $\mathrm{pH}$ value. This agrees with Basir et al. ${ }^{(15)}$ who observed a negative correlation between $\mathrm{pH}$ with nickel or chromium levels either at the baseline or at 2 months.

In both parts of this study, the differences between the groups were significant. This can be taken as an indication of the biodegradation of $\mathrm{Ni}$ and $\mathrm{Cr}$ from the trimmed multiple SSCs in the saliva, but it appears that the SSCs do not release significant amounts of these ions over a prolonged period of time.

In this study, the differences in the results of released metal ions with some of the studies may be related to the different methodologies, the proportions of the elements in the alloy, the manufacturing of the metal parts, the materials and the sensitivity of analytical techniques used with different lower detection limits. Finally, in vivo, the metal ion released from any metal appliances is also affected by many factors, such as dietary habits, $\mathrm{pH}$, salivary composition, measuring devices, the age of the patients, the time wearing the appliance and microflora ${ }^{(37)}$.

Although the present in-vivo study recorded high peaks level for salivary $\mathrm{Ni}$ and chromium release with these multiple SSCs, those never reached the toxic dose of $10 \mu \mathrm{g} / \mathrm{kg}$ body weight ${ }^{(71)}$ and were still below the levels of daily dietary intake (200$300 \mu \mathrm{g}$ /day for $\mathrm{Ni}$ and $280 \mu \mathrm{g}$ /day for chromium, respectively). But Vreebrug (72) reported that the lethal oral dose for $\mathrm{Ni}$ in humans probably lies between 50 and $500 \mu \mathrm{g} / \mathrm{kg}$ body weight.

\section{RECOMMENDATION}

Further investigations with a larger sample size and a longer follow-up are required to confirm the findings of the current study and the possible biological effect of the use of trimming multiple SSCs on tissues.

\section{CONCLUSION}

The use of multiple SSCs had a significant effect on salivary $\mathrm{pH}, \mathrm{Ni}$, and $\mathrm{Cr}$ ions. The more the increase in the number of SSCs, the more the increase in acidity and release of ions. The peak level of released ions and $\mathrm{pH}$ value showed itself in the first phase; 1day and 1-week post-cementation for in-vitro and in-vivo study, respectively. But, it was still much lower than the levels that would be considered toxic or even reaches the levels of dietary intake.

\section{REFERENCES}

1. Sahoo N, Kailasam V, Padmanabhan S, Chitharanjan AB. In-vivo evaluation of salivary nickel and chromium levels in conventional and self-ligating brackets. Am J Orthod Dentofacial Orthop 2011; 140:340-345.

2. Jurela A, Verzak Ž , Brailo V, Škrinjar I, Sudarević K, Janković B. Salivary Electrolytes in Patients with Metallic and Ceramic Orthodontic Brackets. Acta Stomatol Croat 2018; 52: 32-36.

3. Hussain HD, Sreedevi D, Ajith SD, Goel dP. Nickel release from stainless steel and nickel titanium archwires - An in vitro study. J Oral Biol Craniofac Res 2016; 6: 213-218.

4. Bhaskar V, Subba Reddy VV. Biodegradation of nickel and chromium from space maintainers: An in vitro study. $\mathrm{J}$ Indian Soc Pedod Prev Dent 2010; 28:6-12.

5. Barceloux, D. G. Nickel. J Clin Toxicol 1999; 37:239-258.

6. Norseth T. The carcinogenicity of chromium. Environ Health Perspect 1981; 40:121-130.

7. Randall RC. Preformed metal crowns for primary and permanent molar teeth: review of the literature. Pediatr Dent 2002; 24:489-500.

8. Syed M, Chopra R, Sachdev V. Allergic Reactions to Dental Materials-A Systematic Review. J Clin Diagn Res 2015; 9: ZE04-ZE09. 
9. Yilmaz A, Ozdemir CE, Yilmaz Y. A Delayed Hypersensitivity Reaction to a Stainless Steel Crown: A Case Report. J Clin Pediatr Dent 2012; 36: 235-238.

10. Amini F, Borzabadi Farahani A, Jafari A, Rabbani M. In vivo study of metal content of oral mucosa cells in patients with and without fixed orthodontic appliances. Orthod Craniofac Res 2008; 11:51-56.

11. Grimsdottir MR, Gjerdet NR, Hensten-Pettersen A. Composition and in vitro corrosion of orthodontic appliances. Am J Orthod Dentofacial Orthop 1992; 101:525-32.

12. Wataha JC, Lockwood PE, Khajotia SS, Turner R. Effect of $\mathrm{pH}$ on element release from dental casting alloys. J Prosthet Dent1998; 80:691-698.

13. Kuhta M, Pavlin D, Slaj M, Varga S, Lapter-Varga M, Slaj $\mathrm{M}$, et al. Type of arch wire and level of acidity: Effects on the release of metal ions from orthodontic appliances. Angle Orthod 2009; 79:102-110.

14. Kindelan SA, Day P, Nichol R, Willmott N, Fayle SA. British Society of Paediatric Dentistry. UK National Clinical Guidelines in Paediatric Dentistry: Stainless steel preformed crowns for primary molars. Int J Paediatr Dent 2008; 18:20-28.

15. Basir L, Meshki1 R, Behbudil A, RakhshanV. Effects of Restoring the Primary Dentition with Stainless-Steel Crowns on Children's Salivary Nickel and Chromium Levels, and the Associations with Saliva pH: a Preliminary Before-After Clinical Trial. Biol Trace Elem Res 2018. doi: 10.1007/s12011-018-1376-0. [Epub ahead of print]

16. Barrett RD, Bishara SE, Quinn JK. Biodegradation of orthodontic appliances. Part I. Biodegradation of nickel and chromium in vitro. Am J Orthod Dentofacial Orthop 1993; 103:8-14.

17. Langman M. Safe Upper Levels for Vitamins and Minerals. London: food standards Agency. 2003, p. 177-180.

18. Ripa LW. Nursing caries: A comprehensive review. Pediatr Dent 1988; 10:268-282.

19. Dean JA. McDonald and Avery's Dentistry for the Child and Adolescent. St. Louis: Elsevier Health Sciences; 2015. p.197.

20. Özkaya E, Babuna G. Two cases with nickel-induced oral mucosal hyperplasia: a rare clinical form of allergic contact stomatitis? Dermatol Online J 2011; 17:12.

21. Danaei SM, Safavi A, Roeinpeikar SM, Oshagh M, Iranpour S, Omidkhoda M. Ion release from orthodontic brackets in 3 mouth-washes: an in-vitro study. Am J Orthod Den-tofacial Orthop 2011; 139:730-734.
22. Suárez C, Vilar T, Gil J, Sevilla P. In vitro evaluation of surface topographic changes and nickel release of lingual orthodontic archwires. J Mater Sci Mater Med 2010; 21:675-683.

23. Menek N, Basaran S, Karaman Y, Ceylan G, Sen Tunk E. Investigation of nickel Ion release from stainless steel crowns by square wave voltammetry. Int J Electrochem 2012; 7:6465-6471.

24. Van Hoogstraten IM, Andersen KE, Von Blomberg BM, Boden D, Bruynzeel DP, Burrows D, et al. Reduced frequency of nickel allergy upon oral nickel contact at an early age. Clin Exp Immunol 1991; 85:441 - 445.

25. Bishara SE, Barrett RD, Selim MI. Bio-degradation of orthodontic appliances. Part II. Changes in the blood level of nickel. Am J Orthod Dentofacial Orthop 1993; 103:115-119.

26. Burrows D. Hypersensitivity to mercury, nickel and chromium in relation to dental materials. Int Dent J 1986; 36:30-34.

27. Kalkwarf K. Allergic gingival reaction to esthetic crowns. Quintessence Int Dent Dig 1984; 15:741-745.

28. Lamster IB, Kalfus DI, Steigerwald PJ, Chasens AI. Rapid Loss of Alveolar Bone Associated with Nonprecious Alloy Crowns in Two Patients with Nickel Hypersensitivity. J Periodontol 1987; 58:486-492.

29. Schultz J, Connelly E, Glesne L, Warshaw E. Cutaneous and oral eruption from oral exposure to nickel in dental braces. Dermatitis 2004; 15:154-157.

30. Kodaira H, Ohno K, Fukase N, Kuroda M, Adachi S, Kikuchi M, et al. Release and systemic accumulation of heavy metals from preformed crowns used in restoration of primary teeth. J Oral Sci 2013; 55:161-165.

31. Faccioni F, Franceschetti P, Cerpelloni M, Fracasso ME. In vivo study on metal release from fixed orthodontic appliances and DNA damage in oral mucosa cells. Am J Orthod Dentofacial Orthop 2003; 12:687-693.

32. Wataha J, Lockwood P, Schedle A, Noda M, Bouillaguet $\mathrm{S}$. $\mathrm{Ag}, \mathrm{Cu}, \mathrm{Hg}$ and $\mathrm{Ni}$ ions alter the metabolism of human monocytes during extended low-dose exposures. J Oral Rehabil 2002; 29:133-139.

33. Kulkarni P, Agrawal S, Bansal A, Jain A, Tiwari U, Anand A. Assessment of nickel release from various dental appliances used routinely in pediatric dentistry. Indian J Dent 2016; 7:81-85.

34. Amanna EN, Bhat SS, Hegde SK.An in vitro evaluation of nickel and chromium release from different commercially available stainless steel crowns. J Indian Soc Pedod Prev Dent 2019; 37: 31-38. 
35. Hans R, Thomas S, Garla B, Dagli RJ, Hans MK. Effect of various sugary beverages on salivary $\mathrm{pH}$, flow rate, and oral clearance rate amongst adults. Scientifica 2016; 2016:1-6.

36. Agaoglu G, Arun T, Izgi B, Yarat A. Nickel and chromium levels in the saliva and serum of patients with fixed orthodontic appliances. Angle Orthod 2001; 71:375-379.

37. Downarowicz P, Mikulewicz M. Trace metal ions release from fixed orthodontic appliances and DNA damage in oral mucosa cells by in vivo studies: A literature review. Adv Clin Exp Med 2017; 26:1155-1162.

38. Amini F, Rakhshan V, Mesgarzadeh N. Effects of longterm fixed orthodontic treatment on salivary nickel and chromium levels: a 1-year prospective cohort study. Biol Trace Elem Res 2012; 150:15-20.

39. Amini F, Rakhshan V, Sadeghi P. Effect of fixed orthodontic therapy on urinary nickel levels: a long-term retrospective cohort study. Biol Trace Elem Res 2017; 150:31-36.

40. Khaneh Masjedi M, Niknam O, Haghighat Jahromi N, Javidi P, Rakhshan V. Effects of fixed orthodontic treatment using conventional, copper-included, and epoxycoated nickel-titanium archwires on salivary nickel levels: a double-blind randomized clinical trial. Biol Trace Elem Res 2016; 174:27-31.

41. Khaneh Masjedi M, Haghighat Jahromi N, Niknam O, Hormozi E, Rakhshan V. Effects of fixed orthodontic treatment using conventional (two-piece) versus metal injection moulding brackets on hair nickel and chromium levels: a double-blind randomized clinical trial. Eur J Orthod 2017; 39:17-24.

42. Amini F, Harandi S, Mollaei M, Rakhshan V. Effects of fixed orthodontic treatment using conventional versus metal-injection molding brackets on salivary nickel and chromium levels: a double-blind randomized clinical trial. Eur J Orthod 2015; 37: 522-530.

43. Jurela A, Verzak Ž, Brailo V, Škrinjar I, Sudarević K, Janković B. Salivary Electrolytes in Patients with Metallic and Ceramic Orthodontic Brackets. Acta stomatol Croat 2018; 52:32-36.

44. Tchounwou PB, Yedjou CG, Patlolla AK, Sutton DJ. Heavy Metals Toxicity and the Environment. EXS 2012; 101: 133-164.

45. Anderson RA. Chromium metabolism and its role in disease processes in man. Clin Physiol Biochem 1986;4:31-41

46. Permenter MG, Lewis JA, Jackson DA. Exposure to nickel, chromium, or cadmium causes distinct changes in the gene expression patterns of a rat liver derived cell line. PLoS One 2011; 6:e27730.

47. Platt J, Guzman A, Zuccari A, Thornburg DW, Rhodes BF, Oshida Y, et al. Corrosion behavior of 2205 duplex stainless steel. Am J Orthod Dentofac Orthop 1997; 112:69-79.

48. Dayan AD, Paine AJ. Mechanisms of Chromium Toxicity, Carcinogenicity and Allergenicity: Review of the Literature from 1985 to 2000. Hum Exp Toxicol 2001; 20:439-351.

49. Leonard A, Gerber GB, Jacquet P. Carcinogenicity, mutagenicity and teratogenicity of nickel. Mutat Res 1981; $87: 1-15$.

50. Savolainen H. Biochemical and clinical aspects of nickel toxicity. Rev Environ Health 1996; 11:167-173.

51. Kerousuo H, Kullaa A, Kerousuo E, Kanerva L, HenstenPettersen A. Nickel allergy in adolescents in relation to orthodontic treatment and piercing of ears. Am J Orthod Dentofac Orthop 1996; 109:148-154.

52. Ramazani N, Ahmadi R, Darijani M. Assessment of Nickel Release from Stainless Steel Crowns. J Dent (Tehran). 2014; 11:328-334.

53. Hafez HS, Selim EN, Eid FK, Tawfik WA, Al-Ashkar EA, Mostafa YA. Cytotoxicity, genotoxicity, and metal release in patients with fixed orthodontic appliances: A longitudinal in-vivo study. Am J Orthod Dentofacial Orthop 2011; 140:298-308.

54. Dunlap CL, Vincent SK, Barker BF. Allergic reaction to orthodontic wire - Report of case. J Am Dent Assoc 1986; 118:449-450.

55. Mikulewicz M, Wołowiec P, Loster B, Chojnacka K. Metal ions released from fixed orthodontic appliance affect hair mineral content. Biol Trace Elem Res 2015 ;163:11-18.

56. Eliades T, Athanasiou AE. In vivo aging of orthodontic alloys: implications for corrosion potential, nickel release, and biocompatibility. Angle Orthod 2002 ;72:222-237.

57. Petoumenou E, Arndt M, Keilig L, Reimann S, Hoederath $\mathrm{H}$, Eliades T, et al. Nickel concentration in the saliva of patients with nickel-titanium orthodontic appliances. Am J Orthod Dentofacial Orthop 2009; 135:59-65.

58. Mohamed AA, Ahmed AM, Mahmoud TT. Comparison between Nickel and Chromium Levels in Saliva of Children Having Space Maintainers versus Stainless Steel Crowns (Comparative Study). Int J Sci Res 2016; 5:663-666.

59. Dehouck P, Cordeiro F, Snell J, de la Calle B. State of the art in the determination of trace elements in seawater: a worldwide proficiency test. Anal Bioanal Chem 2016; 408: 3223-3232. 
60. Dwivedi A, Tikku T, Khanna R, Maurya R, Verma G, Murthy R. Release of nickel and chromium ions in the saliva of patients with fixed orthodontic appliance: An invivo study. Natl J Maxillofac Surg 2015; 6: 62-66.

61. Amini F, Jafari A, Amini P, Sepasi S. Metal ion release from fixed orthodontic appliances - an in vivo study. Eur J Orthod 2012; 34:126-130.

62. Amini F, Rakhshan V, Mesgarzadeh N. Effects of longterm fixed orthodontic treatment on salivary nickel and chromium levels: a 1-year prospective cohort study. Biol Trace Elem Res 2012; 150:15-20.

63. Nayak RS, Khanna B, Pasha A, Vinay K, Narayan A, Chaitra K. Evaluation of Nickel and Chromium Ion Release During Fixed Orthodontic Treatment Using Inductively Coupled Plasma-Mass Spectrometer: An In Vivo Study. J Int Oral Health 2015; 7: 14-20.

64. Bhaskar V, Subba Reddy VV. Biodegradation of nickel and chromium from space maintainers. J Indian Soc Pedod Prevent Dent 2010; 28: 6-12.

65. Yu Y, Shironita S, Souma K, Umeda M. Effect of chromium content on the corrosion resistance of ferritic stainless steels in sulfuric acid solution. Heliyon 2018 ; 4: e00958.

66. Singh DP, Sehgal V, Pradhan KL, Chandna A, Gupta R.
Estimation of nickel and chromium in saliva of patients with fixed orthodontic appliances. World J Orthod 2008; 9:196-202.

67. Sfondrini MF, Cacciafesta V, Maffia E, Massironi S, Scribante A, Alberti G, et al. Chromium release from new stainless steel, recycled and nickel free orthodontic brackets. Angle Orthod 2009; 79:361-367.

68. Yassaei S, Dadfarina S, Ahdian H, Moradi F. Nickel and Chromium levels in saliva of patients with fixed orthodontics. Orthodontics (Chic) 2013; 14: e76-81.

69. Kocadereli L, Atac PA, Kale PS, Ozer D. Salivary nickel and chromium in patients with fixed orthodontic appliances. Angle Orthod 2000; 70:431-434.

70. Eliades T, Trapalis C, Eliades G, Katsavrias E. Salivary metal levels of orthodontic patients: a novel methodological and analytical approach. Eur J Orthod 2000; 25:103-106.

71. De MichelL, Riesgo-LE. Comportement electrochinique de Alliages Dentaire Co-Cr at Ni-Cr utilises en Prosthese Fuxee Rev. D'Odonto Stomatol 1978; 7:349-353.

72. Vreeburg KJ, de Groot K, von Blomberg M, Scheper RJ. Induction of immunological tolerance by oral administration of Nickel and Chromium. J Dent Res 1984; 63:124-128. 